\title{
Micro Air Vehicle Nonlinear Simulation
}

\author{
Ahmed AboElezz ${ }^{*}$, Ahmed Desoki $^{\dagger}$ Basman Elhadidi ${ }^{\ddagger}$, Gamal El-Bayoumi ${ }^{\S}$
}

\begin{abstract}
Micro air vehicle (MAV) is very sensitive to the external disturbances which make the prediction of its dynamics a hard task. In this paper there is a description of nonlinear simulation made for the MAV's dynamics prediction. Experimental measured data were used in this Simulink simulation, the Aerodynamics forces and moment, Mass moment of inertia, and propulsion system performance were experimentally measured for an accurate simulation of the MAV. The output from the simulation gave accurate prediction for the MAV dynamics.
\end{abstract}

Keywords: nonlinear, Simulink, MAV, flight dynamics.

\section{Nomenclature}

$\mathbf{F}_{\mathbf{x}} \quad$ Force in $\mathrm{x}$ direction in body axes

$\mathbf{F}_{\mathbf{y}} \quad$ Force in y direction in body axes

$\mathbf{F}_{\mathbf{z}} \quad$ Force in $\mathrm{z}$ direction in body axes

H Angular Moment

I Mass moment of inertia

M Moment

m Mass

q Body axes pitch rate

$\mathrm{u} \quad \mathrm{x}$-Axes velocity

v y-Axes velocity

W Moment of momentum

W Z-Axes velocity

$\mathrm{X} \quad$ Force in $\mathrm{x}$ direction in wind axes

$\mathrm{Y} \quad$ Force in $\mathrm{y}$ direction in wind axes

$\mathrm{Z} \quad$ Force in $\mathrm{z}$ direction in wind axes

$\boldsymbol{\alpha} \quad$ Angle of attack

$\boldsymbol{\beta}$ Banking angle

$\Theta \quad$ Body axes pitch

\section{Introduction}

The numerical calculation and analysis of the aircraft dynamic responses to control inputs and disturbances play an important role in modern airplane design. This led to decrease in structural weight and increase in safety. The Simulink model described below was used to examine the dynamic of BlueBird MAV as shown in Fig.1. The MAV was designed by one of the authors.

Aerodynamics laboratory engineer, IAET, ahmed.helmy.3zz@gmail.com

Assistant professor, Aerospace department, Cairo university, ahmed.m.rashed@gmail.com .

Professor Aerospace department, Cairo university, belhadid@ gmail.com

Professor, Aerospace department, Cairo university, gelbayoumi@yahoo.com 
The experimental data of the MAV will be incorporated in the Simulink model to examine longitudinal stability. The simulation model will determine the MAV response for different control inputs and flow disturbances in the longitudinal direction.

We choose Simulink for the following reasons:

1. It can incorporate the aerodynamic measurements directly in Simulink look up tables.

2. It is integrated with the MatLab numerical solvers (ODE45).

3. Has a virtual reality interface that can be used to visualize the MAV during flight.

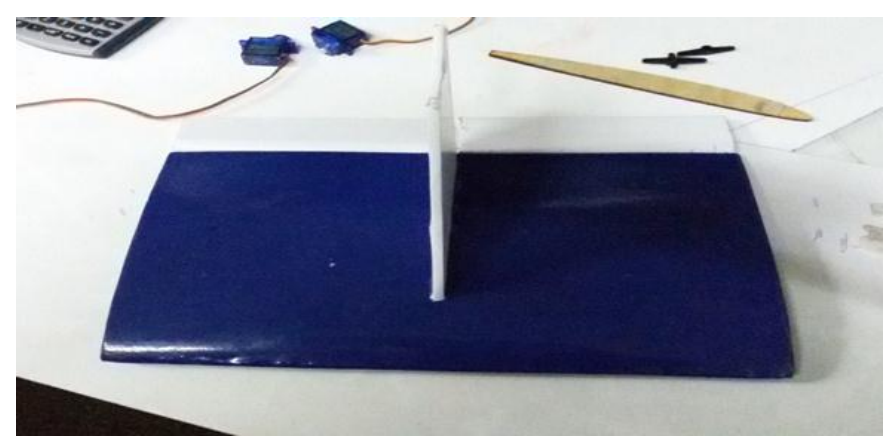

Fig. 1. BlueBird MAV

\section{The Nonlinear Simulation}

\section{MAV Nonlinear Mathematical Model}

Figure 2 represents the MAV motion in the longitudinal direction. The nonlinear aircraft model in the longitudinal direction represented in the following equations. [1] $\rightarrow$ [8]

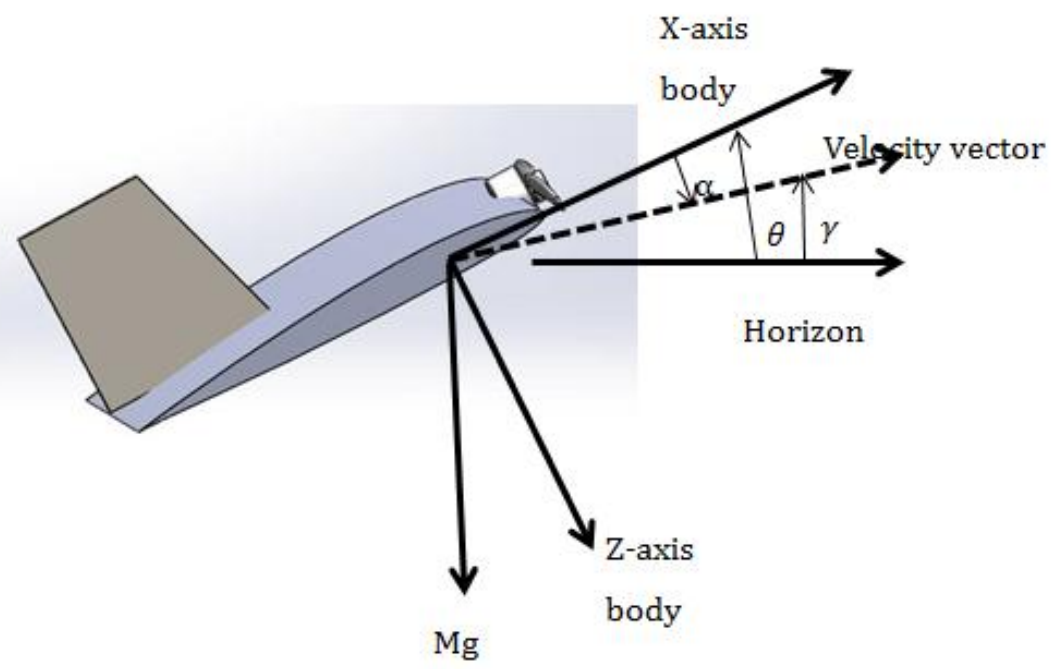

Fig. 2. Longitudinal motion

Apply newton's second law in the MAV body axes

$$
F=m \frac{d V}{d t}+m(\omega \times V)
$$




$$
M=\frac{d H}{d t}+W \times H
$$

The longitudinal direction equations of motion will be:

$$
\begin{aligned}
& u^{\cdot}=\frac{F_{x}}{m}-q w-g \sin \theta \\
& w^{\cdot}=\frac{F_{z}}{m}+q u+g \cos \theta \\
& q^{\cdot}=\frac{M}{I_{y y}} \\
& \theta^{\cdot}=q
\end{aligned}
$$

To include the atmospheric disturbances to the equation of motion $u$ and $w$ should be

$$
\begin{aligned}
& u=u_{M A V}-u_{g} \\
& w=w_{M A V}-w_{g}
\end{aligned}
$$

where $u_{g}$ and $w_{g}$ is the wind gust disturbance velocities

As these equations in body axes and the Aerodynamics forces were measured in wind axes, The following matrix is used to transform the forces between body and wind axis.

$$
\left\{\begin{array}{l}
X \\
Y \\
Z
\end{array}\right\}_{\text {Wind }}=\left[\begin{array}{ccc}
c \alpha c \beta & s \alpha & s \alpha c \beta \\
-c \alpha s \beta & c \beta & -s \alpha s \beta \\
-s \alpha & 0 & c \alpha
\end{array}\right]\left\{\begin{array}{l}
F_{x} \\
F_{y} \\
F_{z}
\end{array}\right\}_{B o d y}
$$

In the case of longitudinal direction only the stability axes will be the wind axes and $\beta=0^{\circ}[7]$.

\section{Experimental Data}

For accurate dynamic simulation Experimental measured data were used. Aerodynamic forces and moment (lift, Drag, Pitching moment versus angle of attack) were measured in an open loop wind tunnel in the Institute of aviation engineering and technology as shown in Fig.3. Example of the measured data is shown in Fig.4, Fig.5 and Fig.6. These data were measured for the MAV with 0 elevator angle and angle of attack range is from -5 to 25 . The experiment was repeated 4 times, both taking the measurements as the angle of attack is increased and decreased to reduce the effects of hysteresis, and to obtain the bounds for experimental uncertainty. The errors bars in the figures represent the standard deviation in the lift, Drag and Moment. The Moment in Fig.6 is measured at the Sting balance moment center not the MAV center of gravity. 


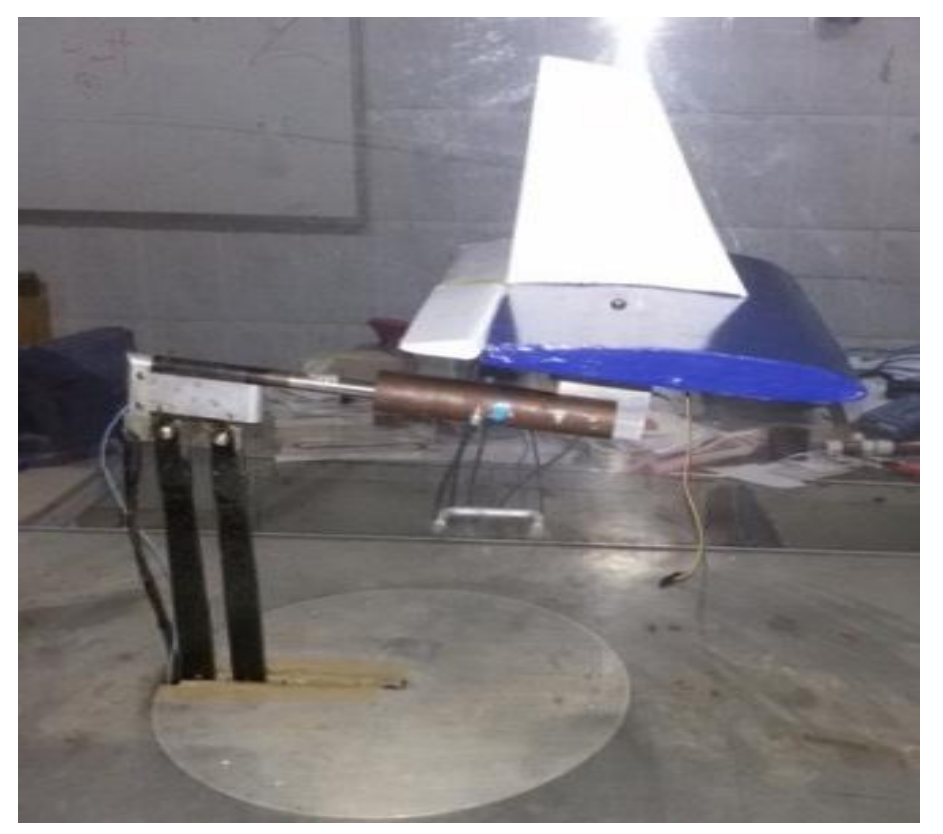

Fig. 3. BlueBird MAV during aerodynamics measurements

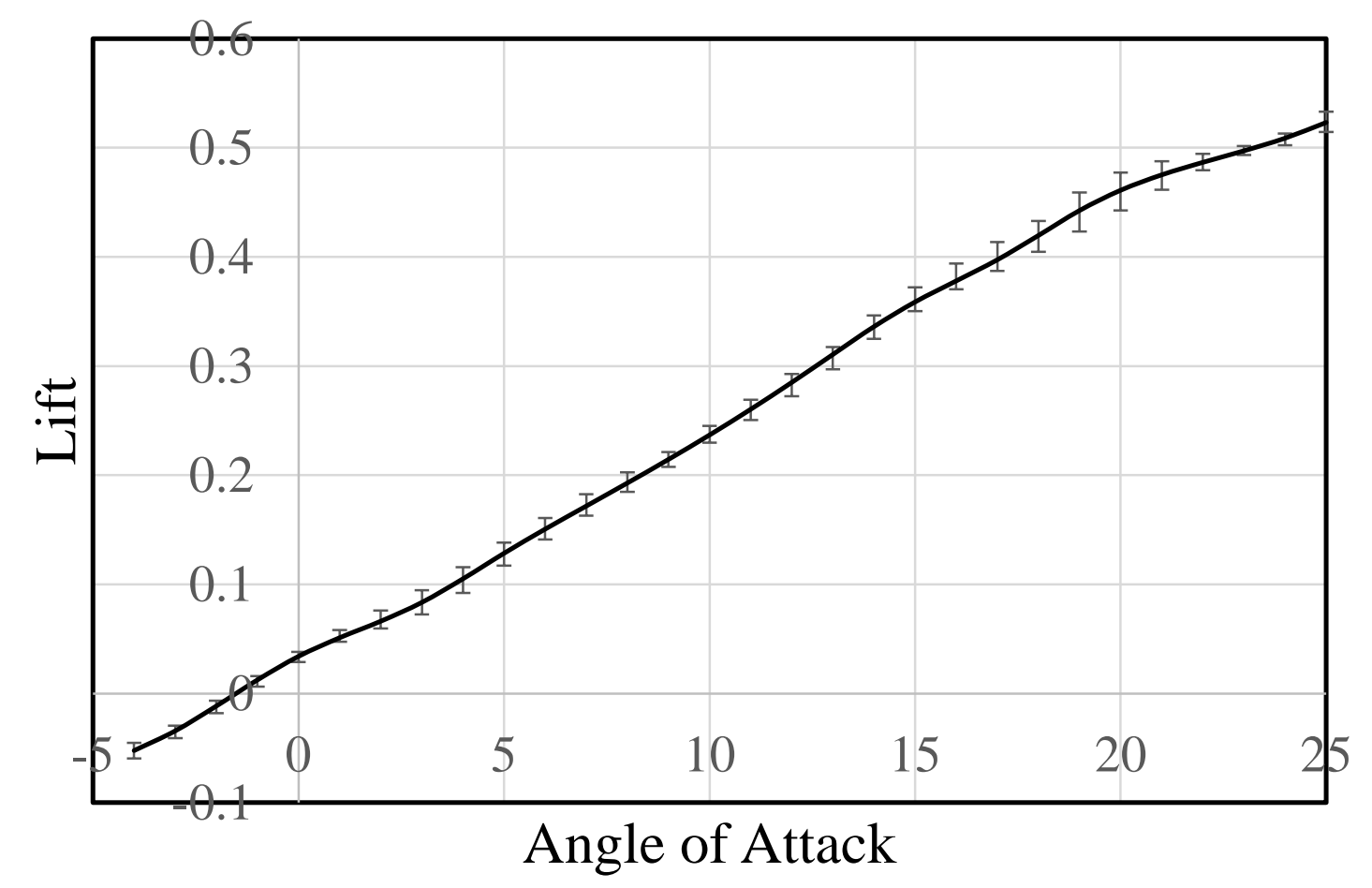

Fig. 4. Lift force in $\mathrm{Kg}$ vs. angle of attack 


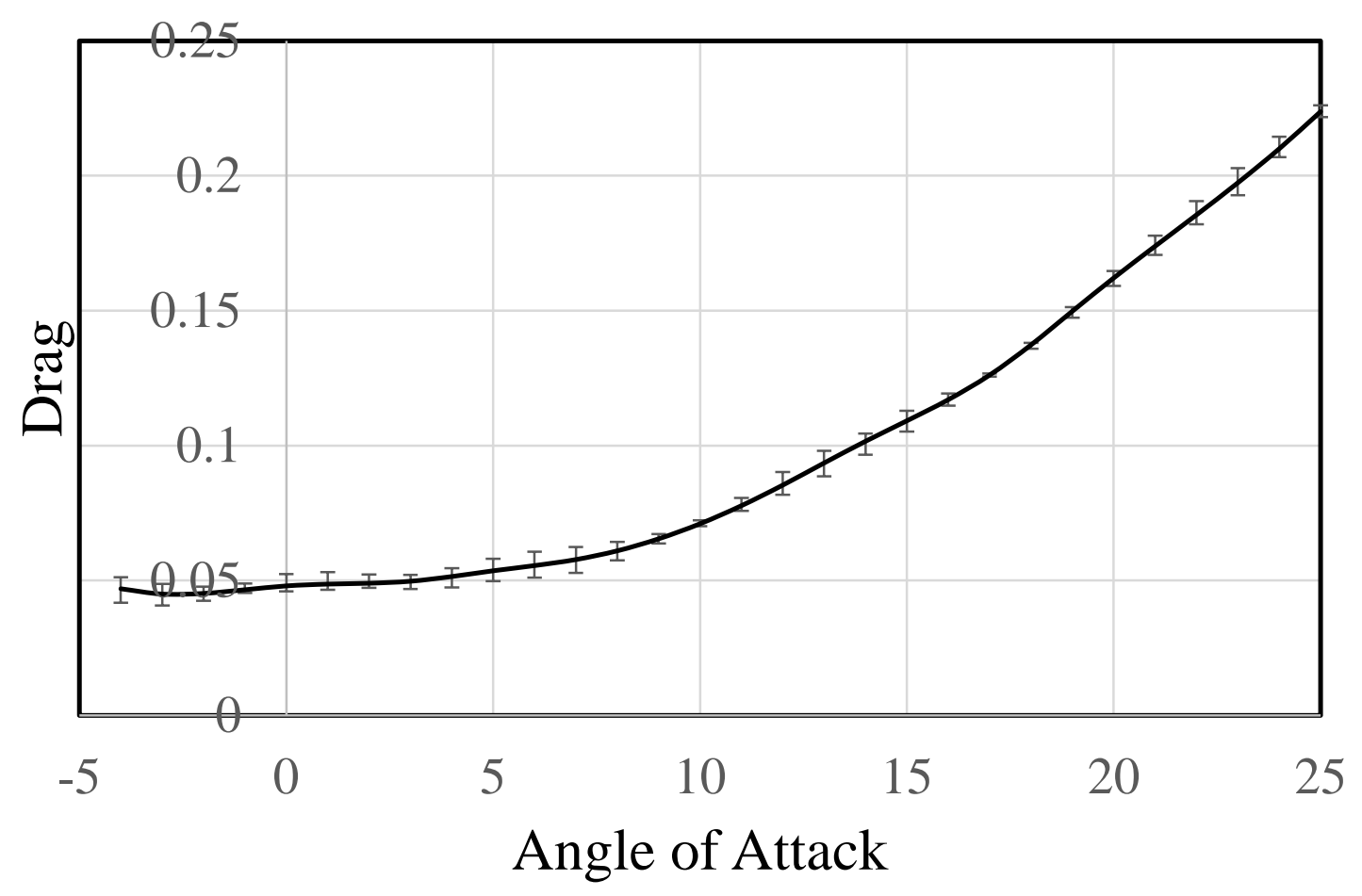

Fig. 5. Drag force in Kg vs. angle of attack

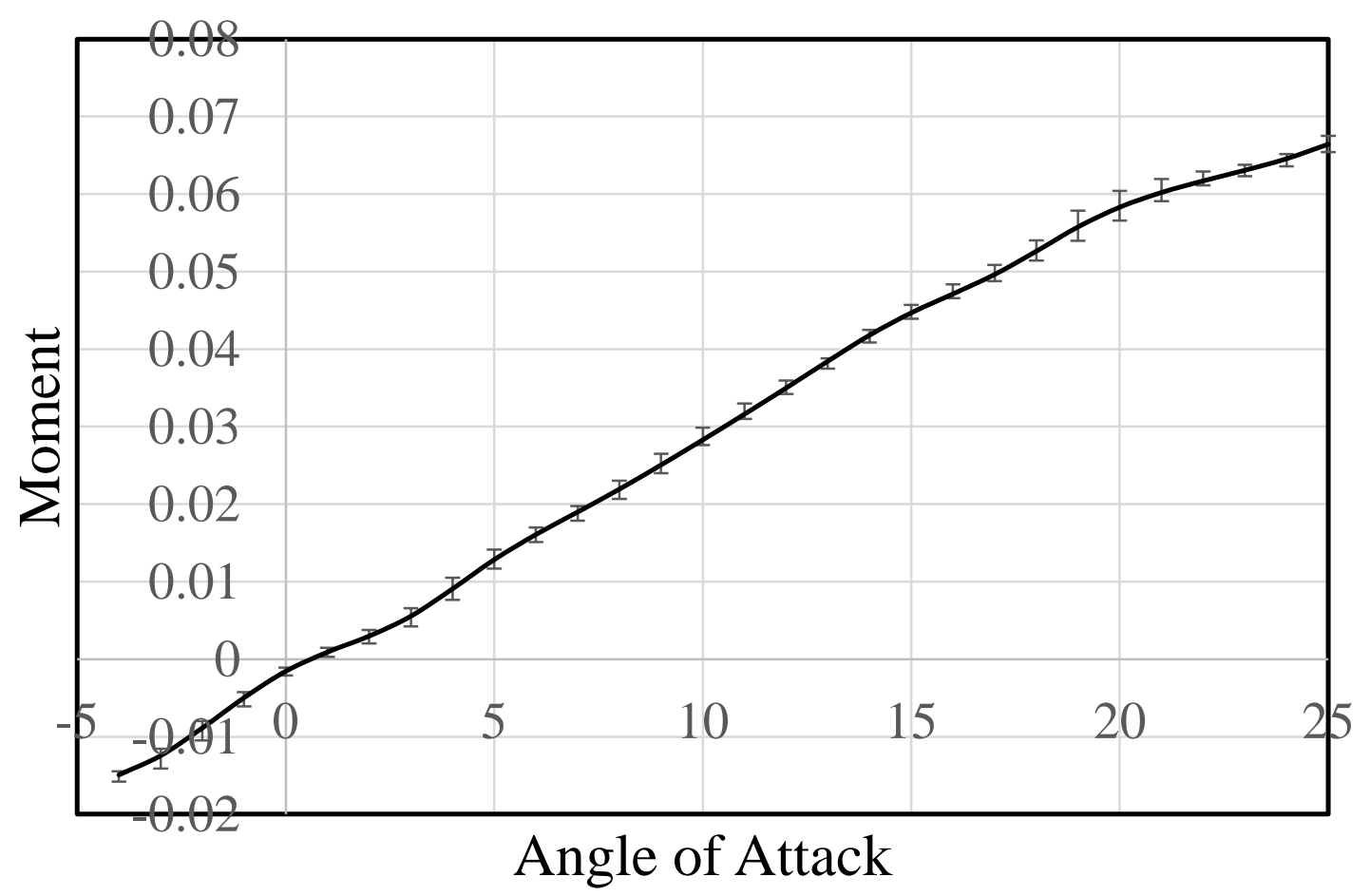

Fig. 6. Moment in $\mathrm{Kg} \times \mathrm{m}$ vs. angle of attack 
Mass moment of inertia and propulsion system performance (thrust versus wind speed) were measured on a special test rigs were designed by the author. The mass moment of inertia test rig is shown in Fig.7.

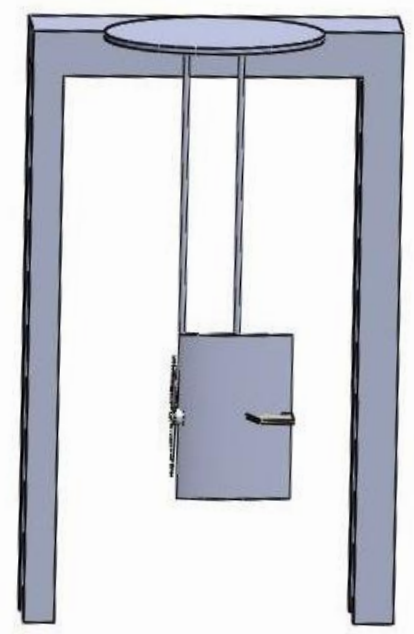

Fig. 7. Bluebird on mass momemt of inertia test rig

\section{The Simulation Simulink Block Diagram}

The designed non-linear model consists of six main blocks, namely: equations of motion, aerodynamic wind axes, wind to body transformations, atmospheric conditions, discrete wind gust model and virtual reality visualizer. An input and an output are defined for each block. The blocks are linked to complete the flight simulation program as shown in Fig.8. The experimental data (lift, Drag, Moment) for different angle of attack and elevator angles were stored in Look up tables in the Aerodynamic wind axis block to enable use it during the simulation. The measured Mass moment of inertia was used in Equation of motion block.

\section{Flight Simulation Results}

MAV Motion animation

One of the Simulink model result is the MAV motion animation using Virtual reality block in the Simulink. These animations give the user an idea about the MAV responses for the different inputs such as control input and disturbance inputs. Figure 9 shows the BlueBird MAV simulation. 


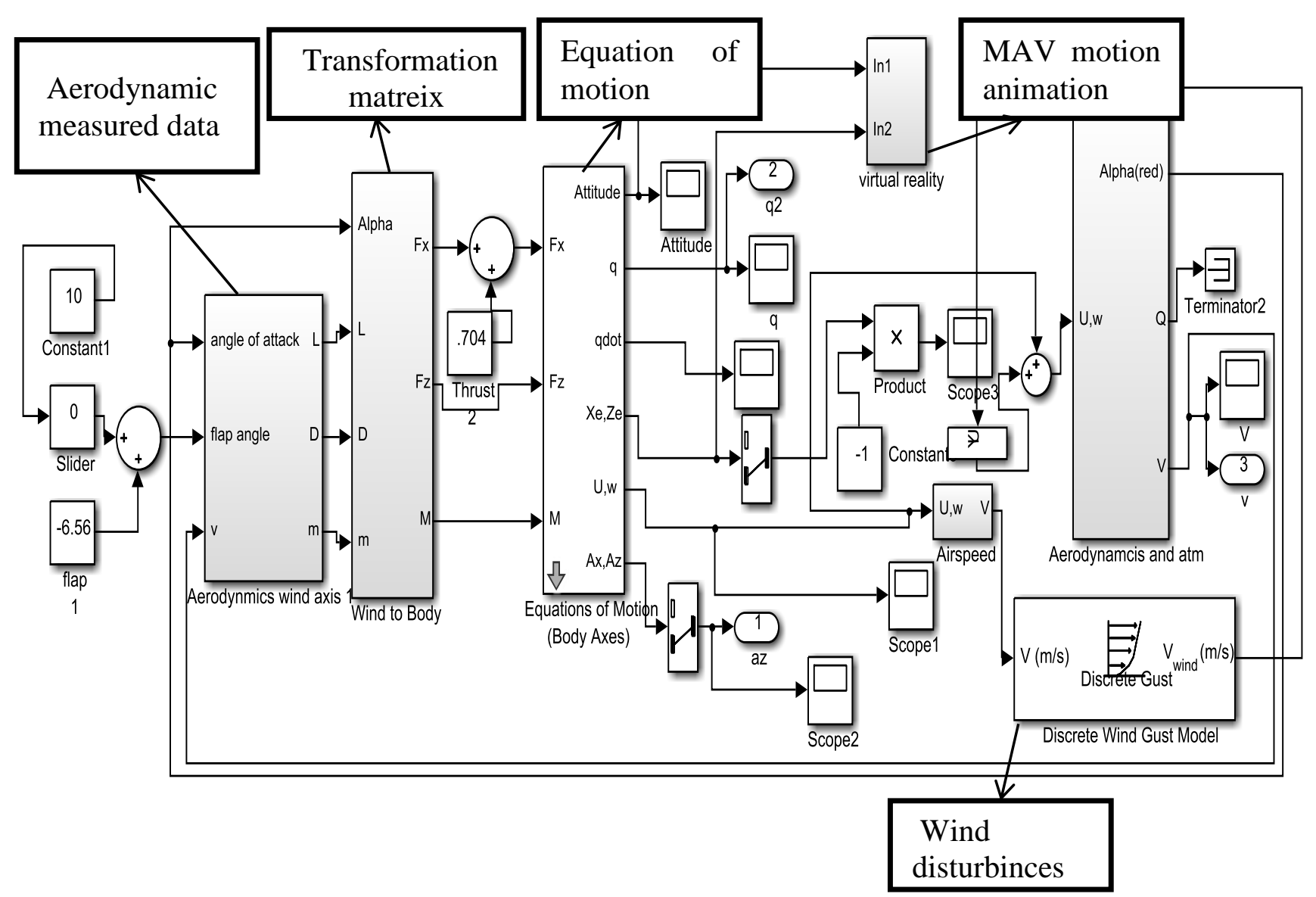

Fig. 8. Block diagram for the Simulink simulation model

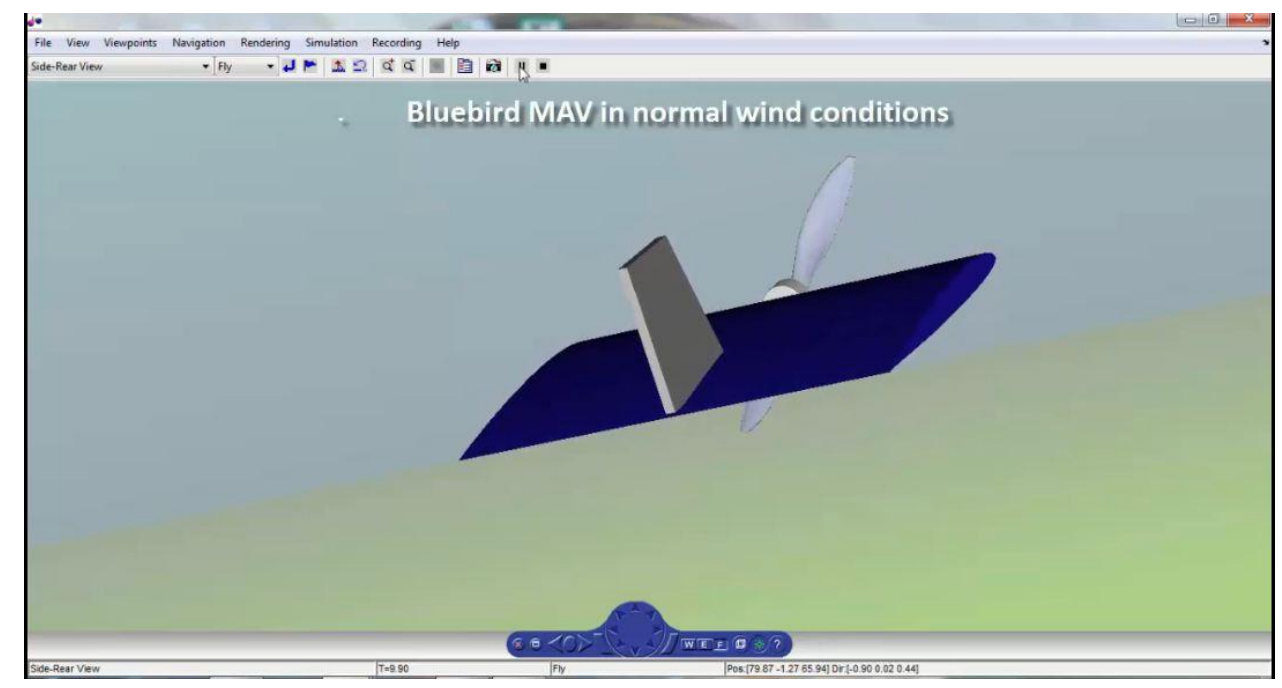

Fig. 9. MAV Flight Simulation

Cruise without wind Disturbance

The motion is simulated without any wind disturbance. The attitude $(\Theta)$ in radian, angular rate (q) in radian per second, velocity (v) in meter per second, and altitude (h) in meter were plotted versus the time. In Fig.10 is the attitude response from the initial conditions. The response is damped and converges with time. 


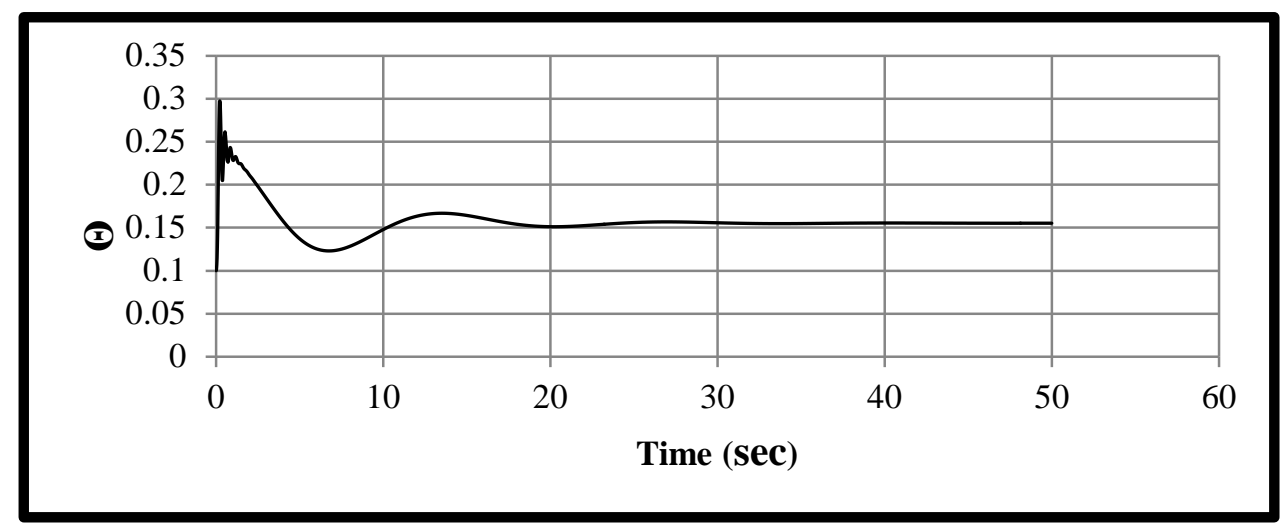

Fig. 10. Attitude response in cruise without wind disturbance

The damped response for the velocity is presented in Fig.11. The Velocity response indicates that the velocity at the steady state is almost $11.5 \mathrm{~m} / \mathrm{s}$. This speed is a result of the elevator angle deflection and the Motor thrust. To reach the required $11 \mathrm{~m} / \mathrm{s}$ it would need a controller.

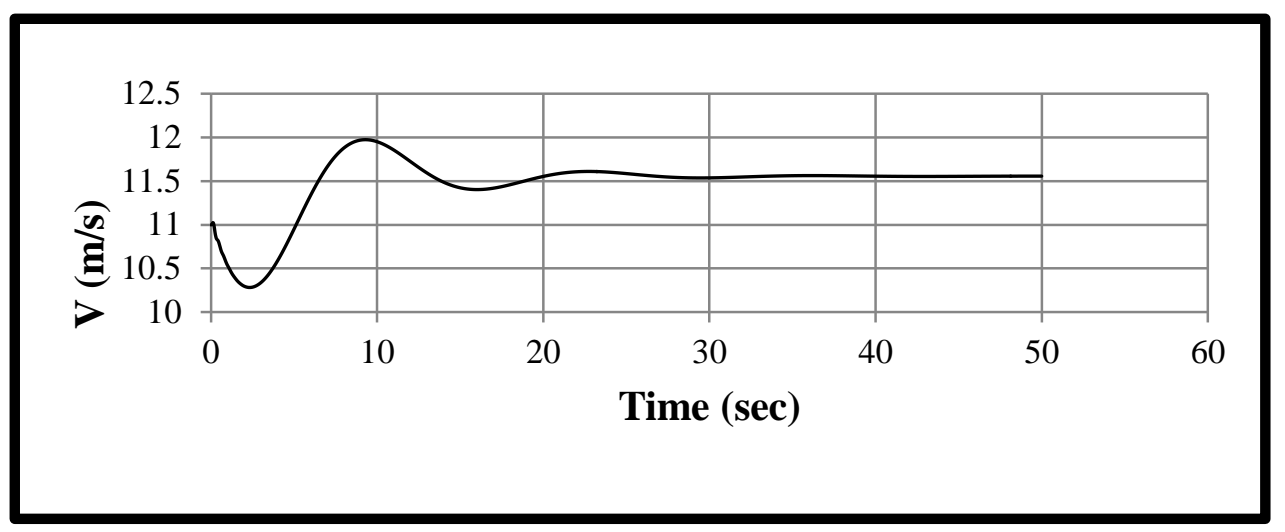

Fig. 11. Velocity response in cruise without wind disturbance

Figure 12 represents the angular rate response, which is a heavy damped but it reached the required angular rate with a value of zero.

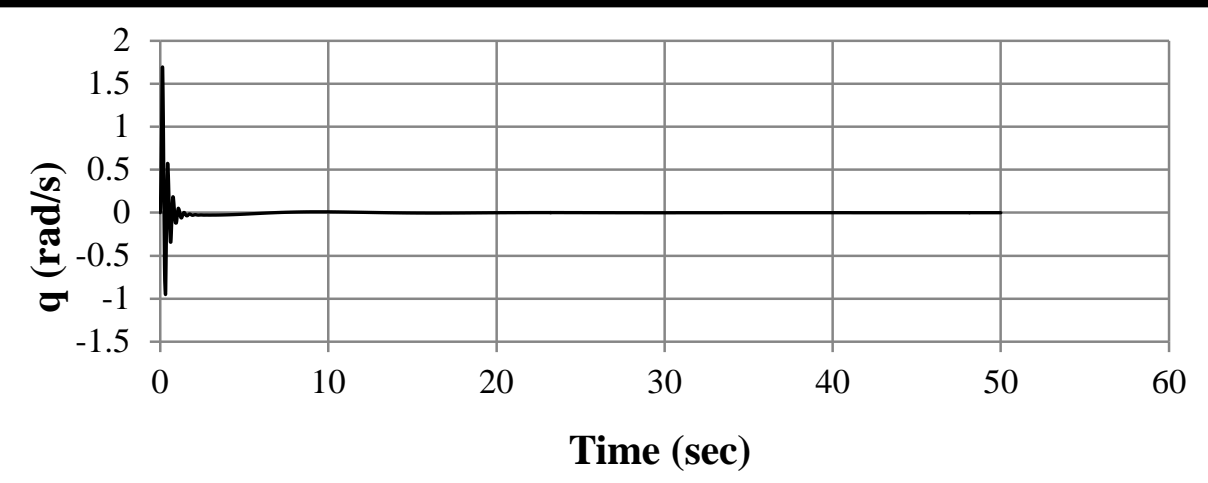

Fig. 12. Angular rate response in cruise without wind disturbance 
In Fig.13 altitude response diverges and is unstable. It requires an altitude hold controller to maintain a constant altitude.

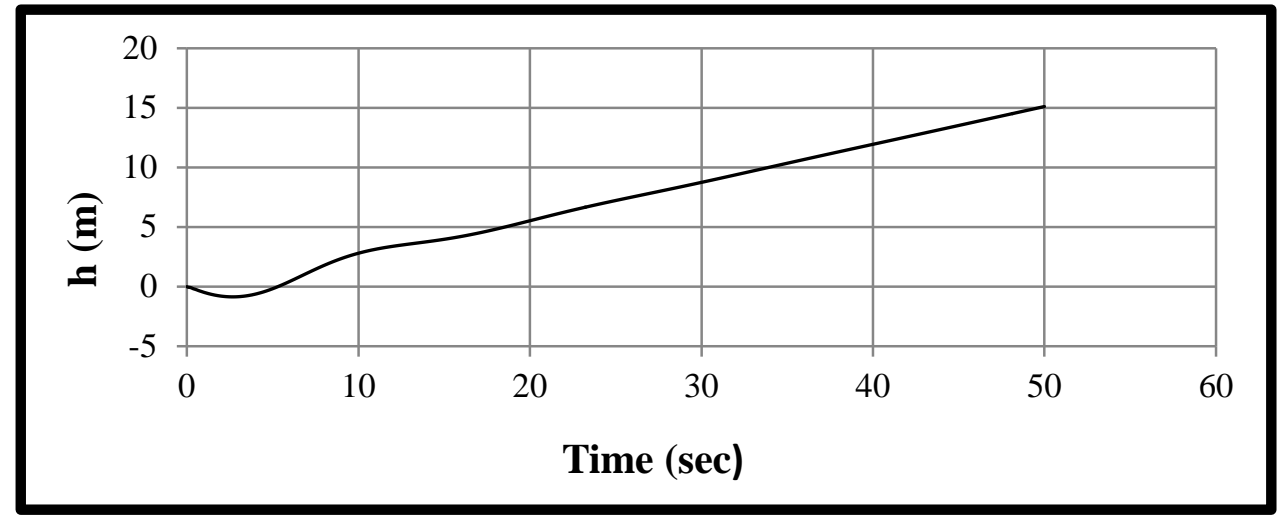

Fig. 13 Altitude response in cruise without wind disturbance

\section{Cruise with Wind Disturbance}

The MAV motion was simulated with $5.5 \mathrm{~m} / \mathrm{s}$ wind disturbance in the X-direction, $3 \mathrm{~m} / \mathrm{s}$ wind disturbance in the Z-direction, and $(2,2) \mathrm{m} / \mathrm{s}$ wind disturbance in $(X, Z)$ direction and this is the maximum disturbances before the MAV stall. Attitude, altitude, velocity and angular rate response were plotted versus the time.

Figure 14 presents the attitude response to the three different wind disturbances. As expected the wind in $\mathrm{z}$ direction made the heights peak and as a result to that it has the higher peak but with the three disturbances the steady state angle is the same. Also in Fig.15 which presents the velocity response. The coupling between attitude and the velocity appears clearly in these two figures. Figure 16 represents the angular rate response. As indicated the MAV needs altitude hold and that appears clearly in Fig.17. The limits of wind gust speed in the three moods were chosen as the maximum values before oscillation diverge.

- $5.5 \mathrm{~m} / \mathrm{s}$ wind in $\mathrm{X}$ $-3 \mathrm{~m} / \mathrm{s}$ wind in $\mathrm{Z} \cdots(2,2) \mathrm{m} / \mathrm{s}$ wind in $\mathrm{X}, \mathrm{Z}$

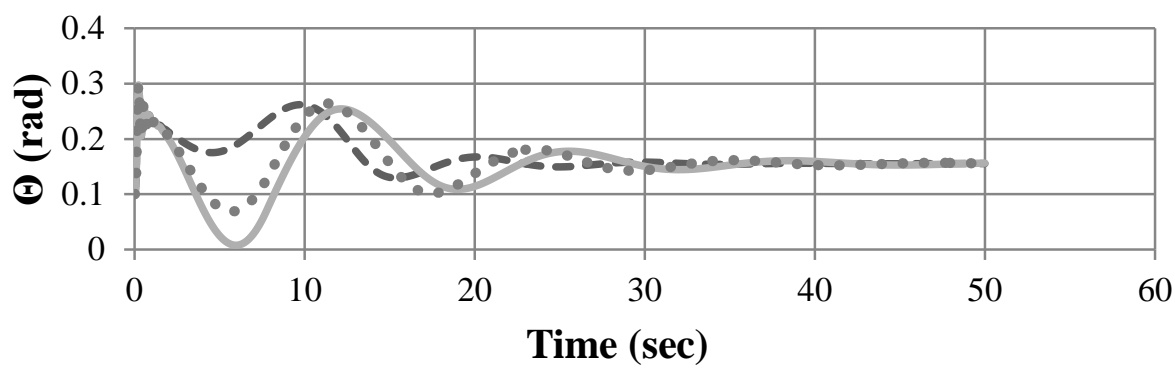

Fig. 14. Attitude response in cruise with different wind disturbance 


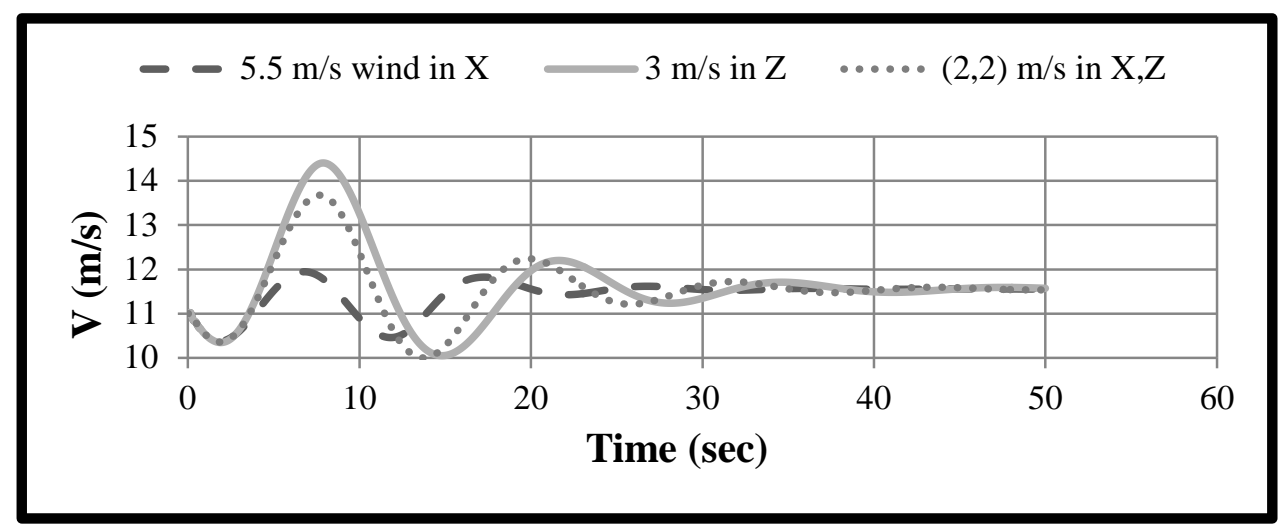

Fig. 15. Velocity response in cruise with different wind disturbance

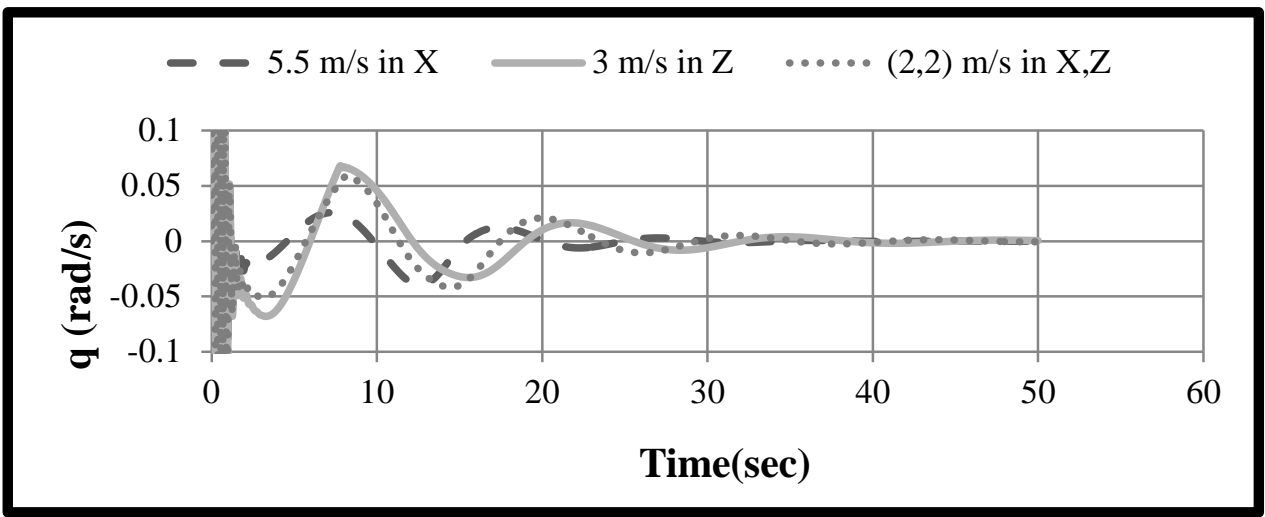

Fig. 16. Angular rate response in cruise with different wind disturbance

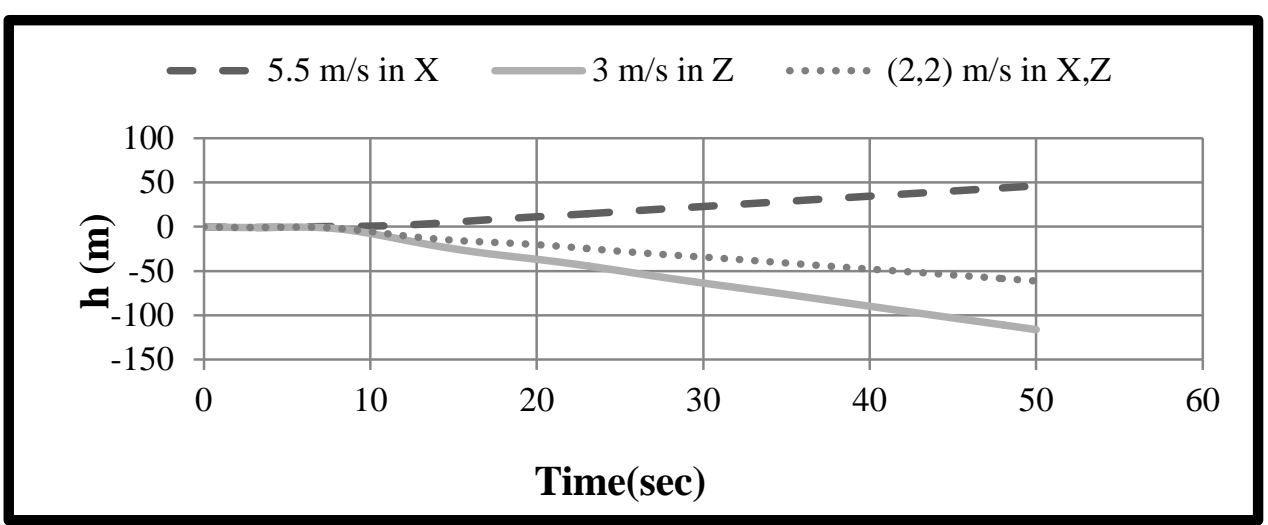

Fig. 17. Altitude response in cruise with different wind disturbance

Cruise from Hand Launch

In the hand launch case, the initial conditions will change for a $4 \mathrm{~m} / \mathrm{s}$ speed as an approximation for the applied force by hand on the MAV and the different responses were plotted below.

Figure 18 indicates the attitude response in the hand launch mode. The velocity response is shown in Fig.19. Figure 20 indicates the angular rate response in hand launch mode. The MAV had velocity loss and this would result altitude loss as shown in Fig.21. 


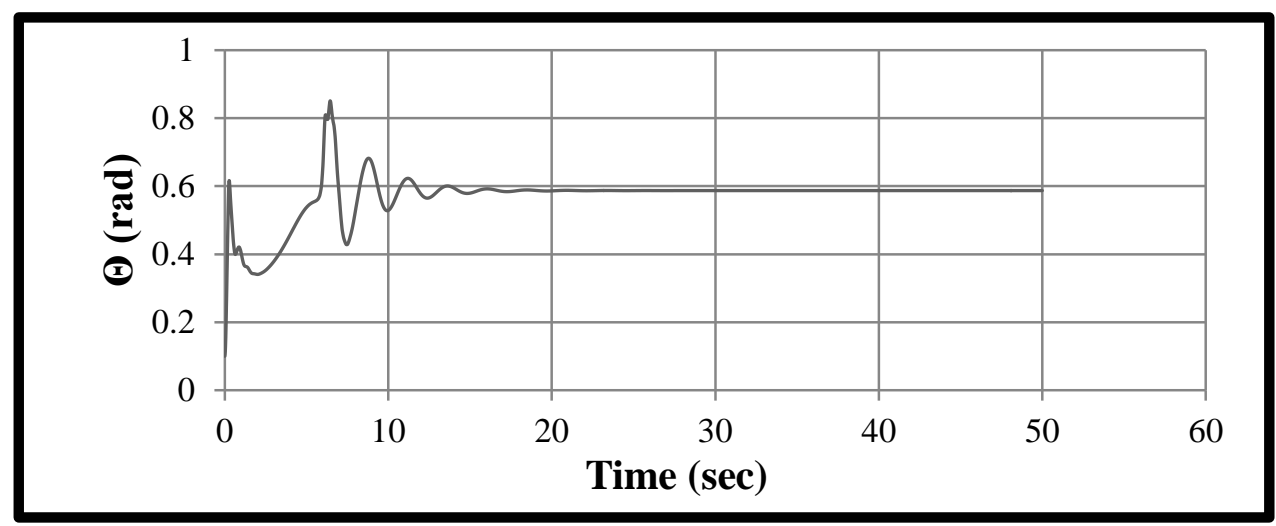

Fig. 18 Attitude response in hand launch

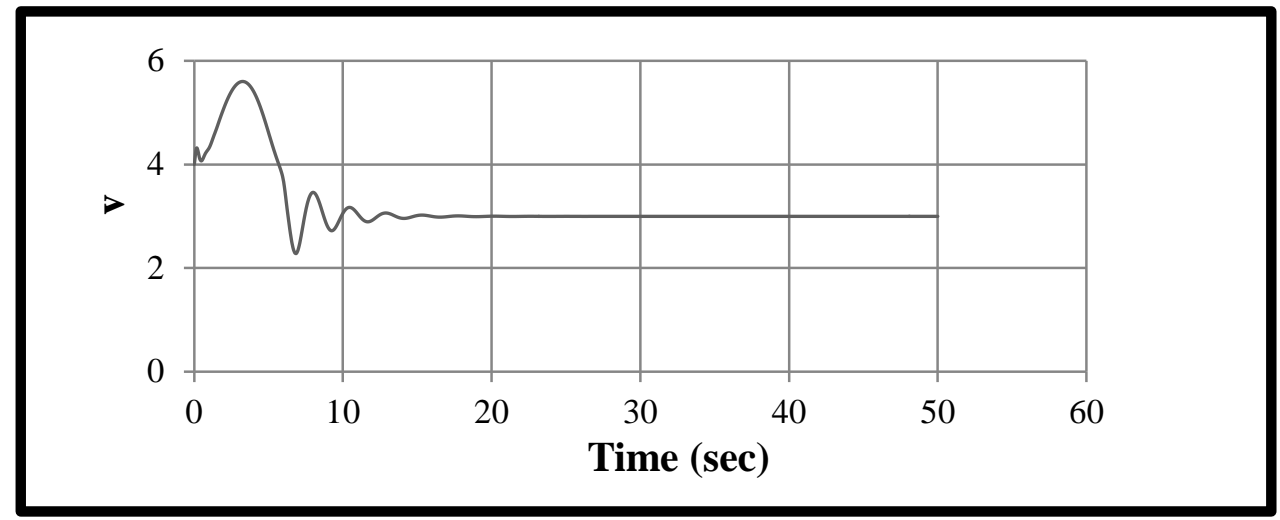

Fig. 19 Velocity response in hand launch

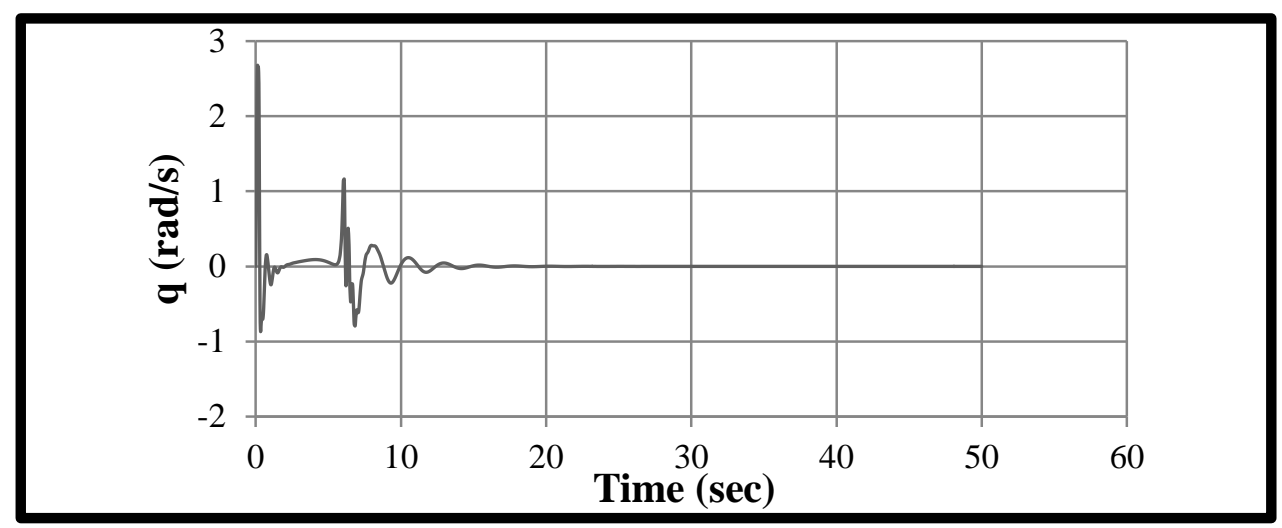

Fig. 20. Angular rate response in hand launch

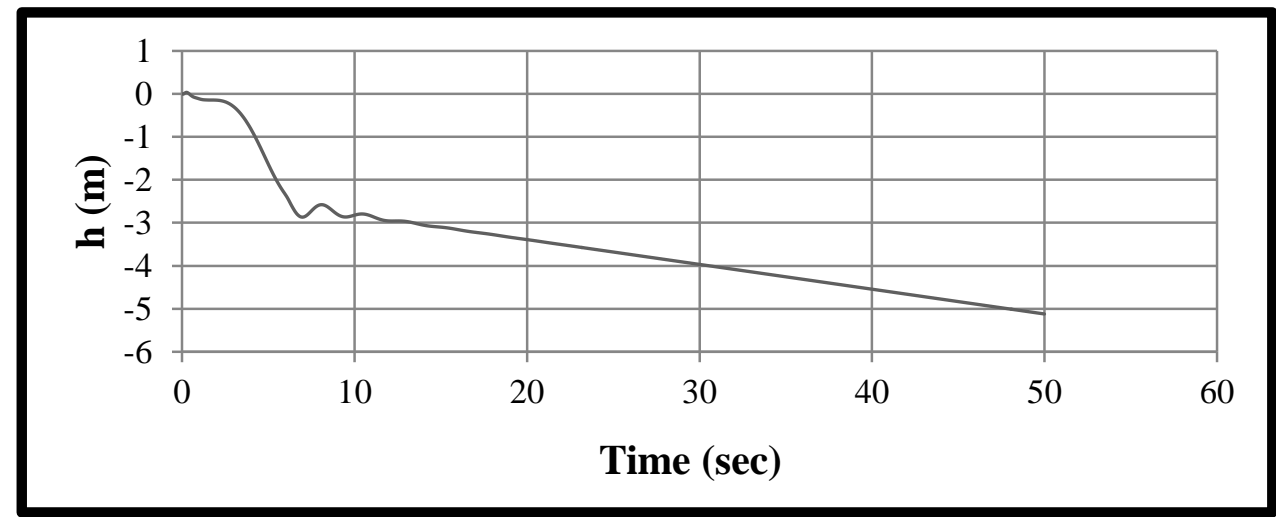

Fig. 21. Altitude rate response in hand launch 
Elevator Input Response

The MAV motion was simulated with impulse input by the elevator and the different responses were plotted against time in Fig.22, Fig.23, Fig.24 and Fig.25. This small elevator is the maximum limit before the MAV response tends to be unstable.

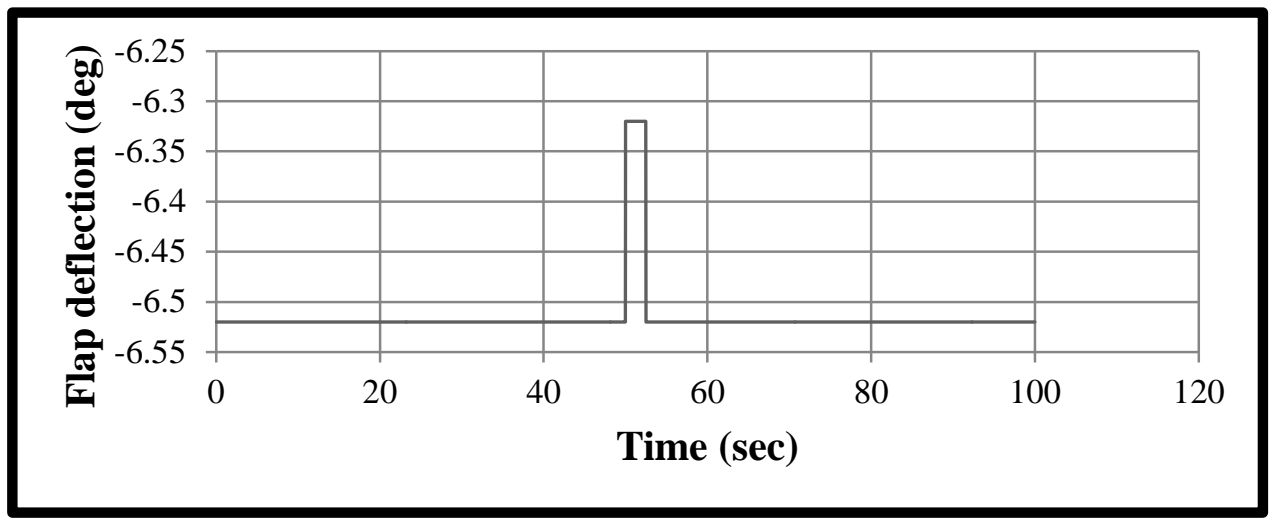

Fig. 22. Impulse input by the elevator

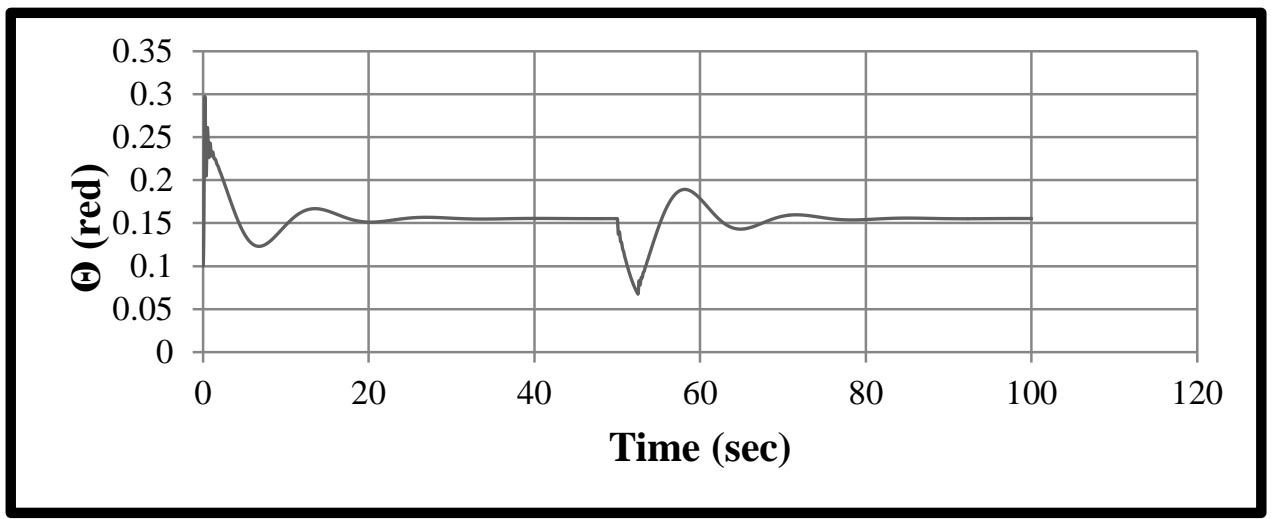

Fig. 23 Attitude response in cruise with impulse input by the elevator

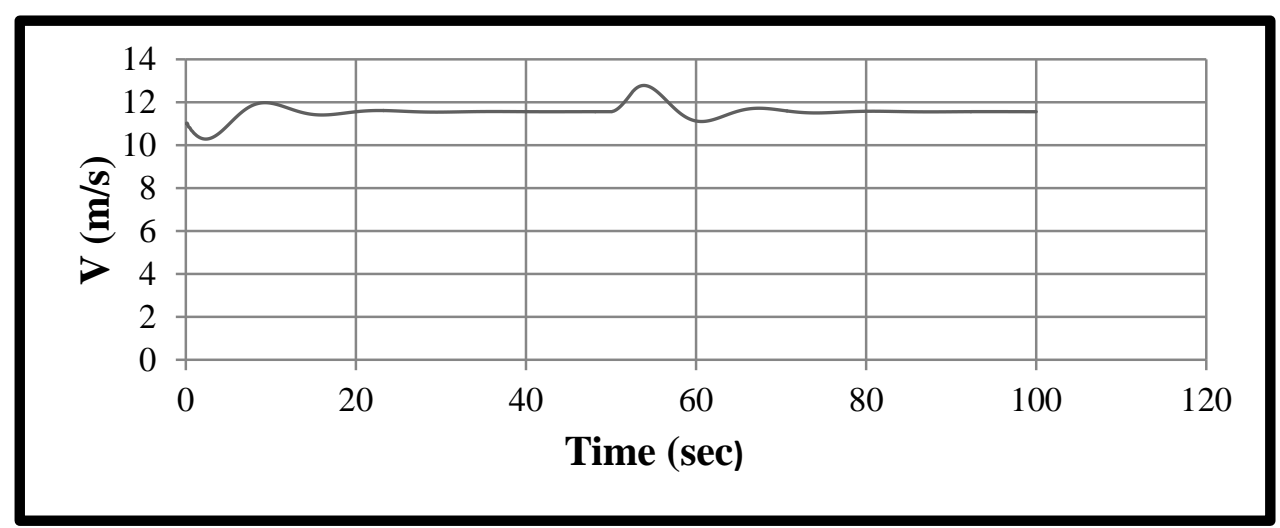

Fig. 24. Velocity response in cruise with impulse input by the elevator 


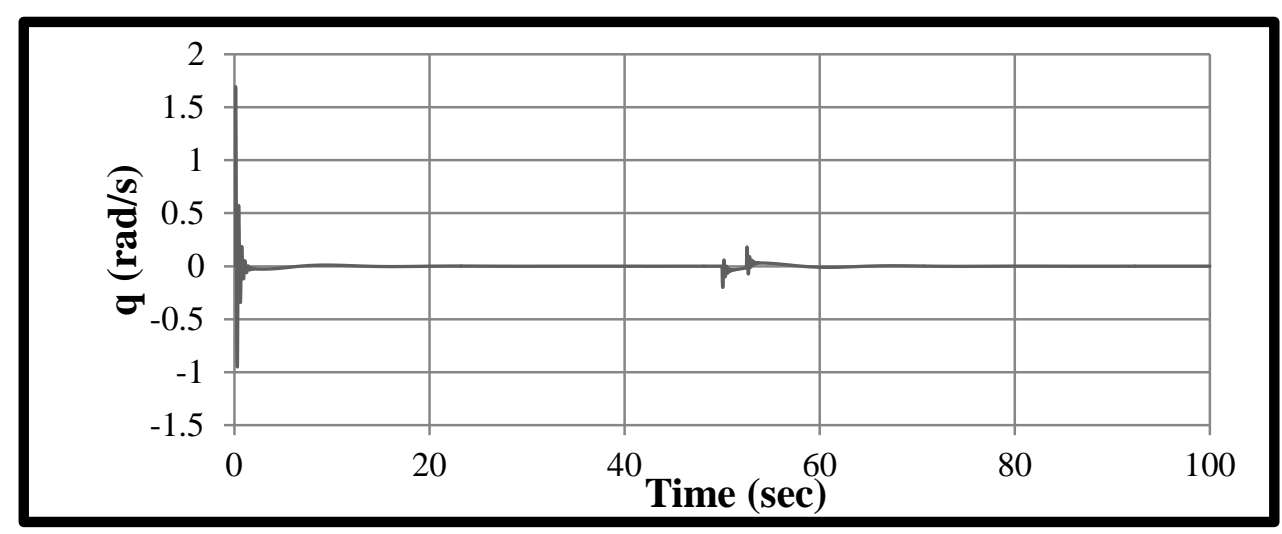

Fig. 25. Angular rate response in cruise with impulse input by the elevator

\section{Flight Simulation Results Discussion and Conclusion}

Nonlinear simulation could be made by Simulink using nonlinear equations of motion. Using experimental measured data such as Aerodynamics and moment of inertia data improved the simulation outputs. The results of different modes related to the dynamics simulations indicate poor stability behavior for the BlueBird MAV. Also, it is very difficult to obtain an operating point do all the required performance and to maintain the MAV stability. It is strongly recommended to design a controller for altitude and speed hold. Also due to the deadline before the conference there was no possibility for making a test flight but it is strongly recommended.

\section{References}

[1] Blockset, 2007. Aerospace Blockset User's Guide. The MathWorks, Inc., Natick, MA.

[2] Elkaim, G.H., Choi, J.W., Garalde, D. and Lizarraga, M., 2008. Control System Modeling and Design for a Mars Flyer, MACH-1 Competition. In AIAA Guidance, Navigation and Control Conference and Exhibit (p. 7453).

[3] Tewari, A., 2007. Atmospheric and space flight dynamics. Birkhũser Boston.

[4] Nelson, R.C., 1998. Flight stability and automatic control (Vol. 2). WCB/McGraw Hill.

[5] Ahmed, U., 2012. 3-DOF Longitudinal Flight Simulation Modeling And Design Using MATLAB/SIMULINK.

[6] Al-Radaideh, A., Al-Jarrah, M.A., Jhemi, A. and Dhaouadi, R., 2009, March. ARF60 AUS-UAV modeling, system identification, guidance and control: Validation through hardware in the loop simulation. In Mechatronics and its Applications, 2009. ISMA'09. 6th International Symposium on (pp. 1-11). IEEE.

[7] Rauw, M.O., 2001. FDC 1.2-A Simulink Toolbox for Flight Dynamics and Control Analysis. Z eist, The $\mathrm{N}$ etherlands, 1(99), p.7.

[8] Stevens, B.L., Lewis, F.L. and Johnson, E.N., 2015. Aircraft Control and Simulation: Dynamics, Controls Design, and Autonomous Systems. John Wiley \& Sons. 